\title{
Groundwater Quality in the Southeast San Joaquin Valley, California
}

Groundwater provides more than 40 percent of California's drinking water. To protect this vital resource, the State of California created the Groundwater Ambient Monitoring and Assessment (GAMA) Program. The Priority Basin Project of the GAMA Program provides a comprehensive assessment of the State's groundwater quality and increases public access to groundwater-quality information. The subbasins in the southeast portion of the San Joaquin Valley constitute one of the study units being evaluated.

\section{The Southeast San Joaquin Valley Study Unit}

The Southeast San Joaquin Valley (SESJ) study unit is located in California's San Joaquin Valley and includes parts of Fresno, Kings, and Tulare Counties. The approximately 3,780-square-mile study unit was divided into four study areas: Kings, Kaweah, Tulare Lake, and Tule. The boundaries of these study areas correspond to the groundwater subbasins with the same names (California Department of Water Resources, 2003; Burton and Belitz, 2008). The SESJ study unit has hot, dry summers and cool, moist winters. Average annual rainfall ranges from 7 to 13 inches. The San Joaquin, Kings, and Tule Rivers are the primary streams flowing through the study unit. These rivers originate in the Sierra Nevada to the east.

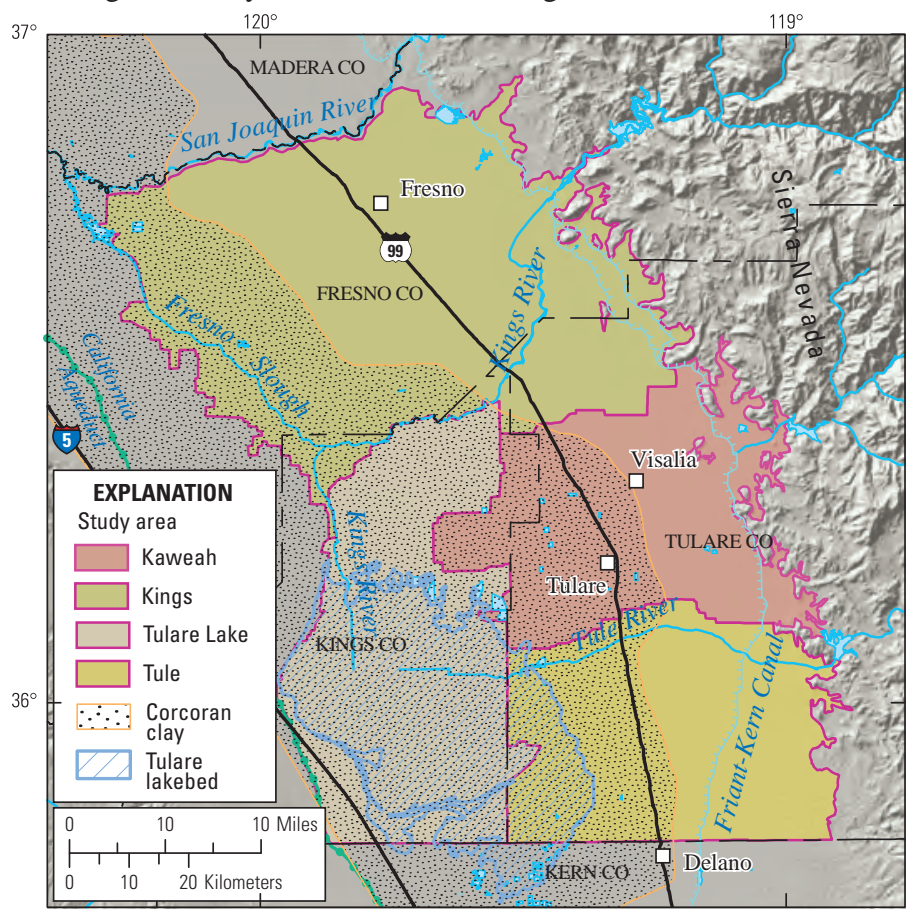

The primary aquifers consist of alluvial sediments (mixtures of sand, silt, clay, cobbles, and boulders), and continental deposits (poorly consolidated sand, gravel, and clay). Downward flow of groundwater is impeded by a subsurface clay layer known as the Corcoran clay in the western part of the SESJ study unit. The primary aquifers are defined as those parts of the aquifers corresponding to the perforated intervals of wells listed in the California Department of Public Health database. Public-supply wells are typically drilled to depths between 350 and 700 feet below land surface, con-

sist of solid casing from the land surface to a depth of about 150-400 feet, and are perforated or screened below the solid casing. Water quality in the shallower and deeper parts of the aquifer system may differ from that in the primary aquifers.

Land use in the study unit is approximately 85 percent (\%) agricultural, 6\% urban, and 9\% natural. The primary agricultural uses are for orchards, vineyards, cotton, and dairies. The largest urban areas are the cities of Fresno, Visalia, and Tulare.

The primary source of recharge to the groundwater flow system is runoff from the nearby Sierra Nevada (Faunt, 2009). Other sources of recharge include percolation of irrigation return water, precipitation, urban runoff, and irrigation canals (California Department of Water Resources, 2003; Wright and others, 2004). The primary sources of groundwater discharge are water pumped for irrigation and municipal supply. About $40 \%$ of the water used in the SESJ study unit comes from groundwater (California Department of Water Resources, 2003).

\section{Overview of Water Quality}
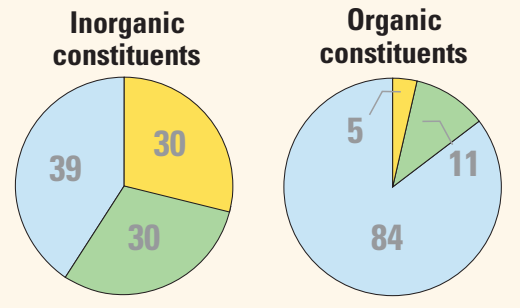

CONSTITUENT CONCENTRATIONS

High $\bigcirc$ Moderate $\bigcirc$ Low or not detected

Values are a percentage of the area of the primary aquifers with concentrations in the three specified categories. Values on piechart may not equal $\mathbf{1 0 0}$ due to rounding of percentages.

GAMA’s Priority Basin Project evaluates the quality of untreated groundwater. However, for context, benchmarks established for drinking-water quality are used for comparison. Benchmarks and definitions of high, moderate, and low concentrations are discussed in the inset box on page 3 .

Many inorganic constituents occur naturally in groundwater. The concentrations of inorganic constituents can be affected by natural processes as well as by human activities. In the Southeast San Joaquin Valley study unit, one or more inorganic constituents were present at high concentrations in 30\% of the primary aquifers and at moderate concentrations in 30\%.

Organic constituents are found in products used in the home, business, industry, and agriculture. Organic constituents can enter the environment through normal usage, spills, or improper disposal. In this study unit, one or more organic constituents were present at high concentrations in 5\% of the primary aquifers and at moderate concentrations in $11 \%$. 


\section{INORGANIC CONSTITUENTS}

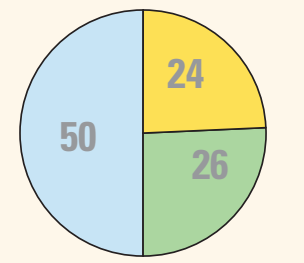

Trace and minor elements

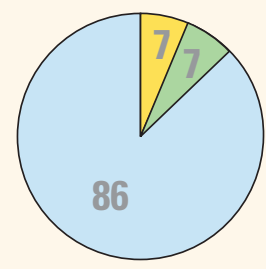

Uranium and radioactive constituents

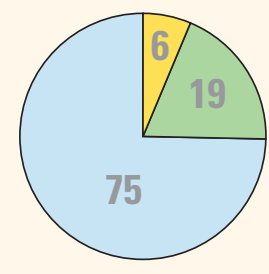

Nutrients
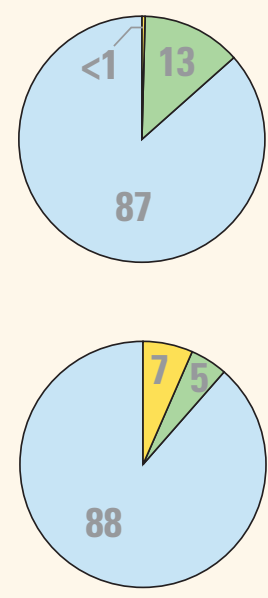

Iron or manganese

SPECIAL-INTEREST CONSTITUENTS

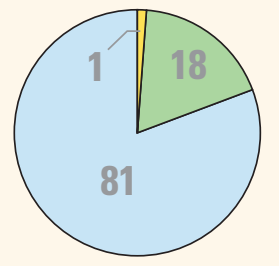

\section{Inorganic Constituents with Human-Health Benchmarks}

Trace and minor elements are naturally present in the minerals in rocks and soils, and in the water that comes into contact with those materials. In the SESJ study unit, trace elements were present at high concentrations in $24 \%$ of the primary aquifers, and at moderate concentrations in 26\%. Arsenic, boron, and vanadium were the trace elements that most frequently occurred at high concentrations. Aluminum, barium, and lead also were detected at high concentrations, but in less than $(<) 2 \%$ of the primary aquifers.

Radioactivity is the release of energy or energetic particles during structural changes in the nucleus of an atom. Most of the radioactivity in groundwater comes from decay of naturally occurring isotopes of uranium and thorium in minerals in the aquifer sediments. Radioactive constituents were present at high concentrations in $7 \%$ of the primary aquifers, and at moderate concentrations in $7 \%$. The radioactive constituent that was detected at high levels was uranium.

Nutrients, such as nitrate and nitrite, are naturally present at low concentrations in groundwater. High and moderate concentrations generally occur as a result of human activities, such as applying fertilizer to crops. Livestock, when in concentrated numbers, and septic systems also produce nitrogenous waste that can leach into groundwater. Nitrate was present at high concentrations in 6\% of the primary aquifers, and nitrate was present at moderate concentrations in 19\% of the primary aquifers.

\section{Inorganic Constituents with Non-Health Benchmarks}

(Not included in water-quality overview charts shown on the front page)

Some constituents, such as total dissolved solids (TDS), affect the aesthetic properties of water, such as taste, color, and odor. Other constituents, such as iron and manganese, can create nuisance problems, such as scaling and staining.

The State of California has a recommended and an upper limit for TDS in drinking water. In the SESJ study unit, TDS was present at high concentrations (above the upper limit) in less than 1\% of the primary aquifers, and at moderate concentrations (between the recommended and upper limit) in 13\% of the primary aquifers.

Iron and manganese are naturally occurring elements, and one or both were present at high concentrations in $7 \%$ of the primary aquifers. Iron, manganese, or both were present at moderate concentrations in 5\% of the primary aquifers.

\section{Perchlorate and $\boldsymbol{N}$-Nitrosodimethylamine (NDMA)}

(Not included in water-quality overview charts shown on the front page)

Perchlorate, an inorganic constituent, and NDMA, a semi-volatile organic compound, are of special interest in California because these constituents have recently been found in or are considered to have the potential to affect drinkingwater supplies. Their presence in groundwater is monitored by the California Department of Public Health (http://www.cdph.ca.gov). In the SESJ study unit, perchlorate was present at high concentrations in 1\% of the primary aquifers, and at moderate concentrations in about 18\%. NDMA was not present at high concentrations, but was present at moderate concentrations in $3 \%$ of the primary aquifers. 


\section{RESULTS: Groundwater Quality in the Southeast San Joaquin Valley Study Unit}

\section{ORGANIC CONSTITUENTS}

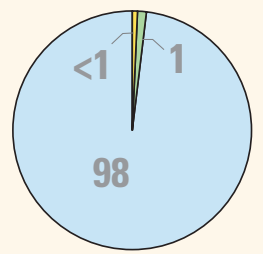

Solvents

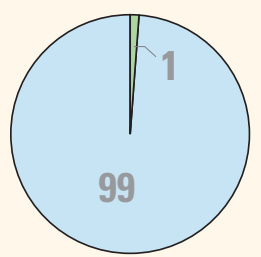

Trihalomethanes

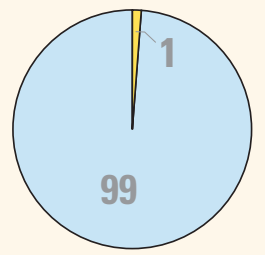

Other volatile organic compounds

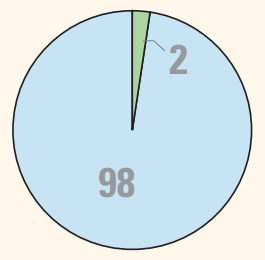

Pesticides

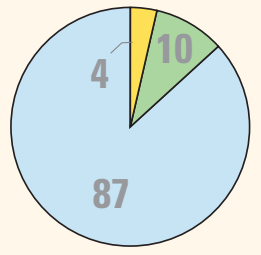

\section{Organic Constituents}

The Priority Basin Project uses laboratory methods that can detect low concentrations of volatile organic compounds (VOCs) and pesticides, far below human-health benchmarks. VOCs and pesticides detected at these very low concentrations can be used to help trace water from the landscape into the aquifer system.

\section{Volatile Organic Compounds with Human-Health Benchmarks}

VOCs are in many household, commercial, industrial, and agricultural products and are characterized by their tendency to volatilize into the air.

Solvents are used for a number of purposes, including manufacturing and cleaning. In the SESJ study unit, solvents were present at high concentrations in $<1 \%$ of the primary aquifers. The solvents found at high concentrations were carbon tetrachloride, tetrachloroethene, and trichloroethene. Solvents were present at moderate concentrations in $1 \%$ of the primary aquifers and were at low concentrations or not detected in $98 \%$.

Trihalomethanes may form during water purification and can enter groundwater by the infiltration of landscape irrigation water. Trihalomethanes were present at moderate concentrations in $1 \%$ of the primary aquifers, and were at low concentrations or not detected in $99 \%$.

Other VOCs include organic synthesis reagents, gasoline hydrocarbons, and refrigerants. Other VOCs were present at high concentrations in $1 \%$ of the primary aquifers, and were at low concentrations or not detected in 99\%. The VOC found at high concentrations was benzene, a gasoline hydrocarbon.

\section{Pesticides with Human-Health Benchmarks}

Pesticides are applied to crops, gardens, lawns, around buildings, and along roads to help control unwanted vegetation, insects, fungi, and other pests. In the SESJ study unit, pesticides (not including fumigants) were not detected at high concentrations in the primary aquifers, but the insecticide, dieldrin, was detected at moderate concentrations in $2 \%$ of the primary aquifers.

Fumigants were present at high concentrations in about $4 \%$ of the primary aquifers. The fumigant 1,2-dibromo-3-chloropropane (DBCP) was the only fumigant detected at high concentrations. Fumigants (primarily DBCP) were present at moderate concentrations in $10 \%$ of the primary aquifers. Use of DBCP as a soil fumigant was discontinued in California in 1977.

\section{BENCHMARKS FOR EVALUATING GROUNDWATER OUALITY}

GAMA’s Priority Basin Project uses benchmarks established for drinking water to provide context for evaluating the quality of untreated groundwater. After withdrawal, groundwater may be disinfected, filtered, mixed, and exposed to the atmosphere before being delivered to consumers. Federal and California regulatory benchmarks for protecting human health (Maximum Contaminant Level, MCL) were used when available. Nonregulatory benchmarks for protecting aesthetic properties, such as taste and odor (Secondary Maximum Contaminant Level, SMCL), and nonregulatory benchmarks for protecting human health (Notification Level, NL, and Lifetime Health Advisory, HAL) were used when Federal or California regulatory benchmarks were not available.

\section{High, moderate, and low concentrations are defined relative to benchmarks}

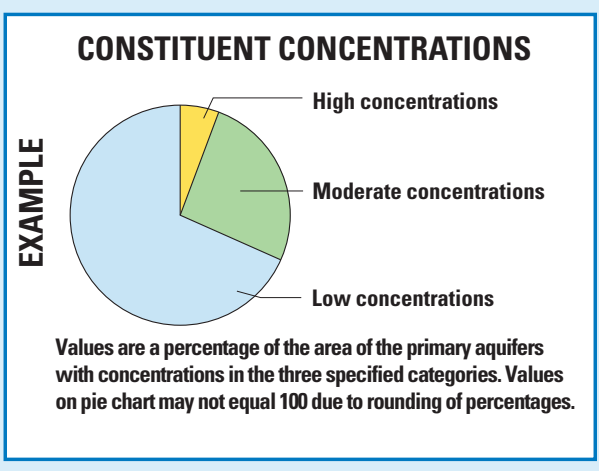

Concentrations are considered high if they are greater than a benchmark. For inorganic constituents, concentrations are moderate if they are greater than one-half of a benchmark. For organic and special-interest constituents, concentrations are moderate if they are greater than one-tenth of a benchmark; this lower threshold was used because organic constituents are generally less prevalent and have smaller concentrations relative to benchmarks than inorganic constituents. Low concentrations include non-detections and values less than moderate concentrations. Methods for evaluating water quality are discussed by Burton and others (2012). 


\section{Factors that Affect Groundwater Quality}

In the SESJ study unit, arsenic is the constituent which most frequently occurs at high concentrations (19\%) in the primary aquifers (Burton and others, 2011). The humanhealth regulatory benchmark for arsenic is 10 micrograms per liter $(\mu \mathrm{g} / \mathrm{L})$. Sources of arsenic in SESJ groundwater are primarily natural, and concentrations are affected by $\mathrm{pH}$ and dissolved oxygen (DO). Arsenic concentrations increase as the $\mathrm{pH}$ increases due to desorption from aquifer sediments. High and moderate concentrations are particularly prevalent in groundwater when the DO concentration is low (less than 1.0 milligram per liter $[\mathrm{mg} / \mathrm{L}]$ ), due to dissolution of oxidized coatings on aquifer sediments (Stollenwerk, 2003). DO that is equal to or less than $1 \mathrm{mg} / \mathrm{L}$ generally occurs in deeper groundwater (more than 250 feet below land surface).
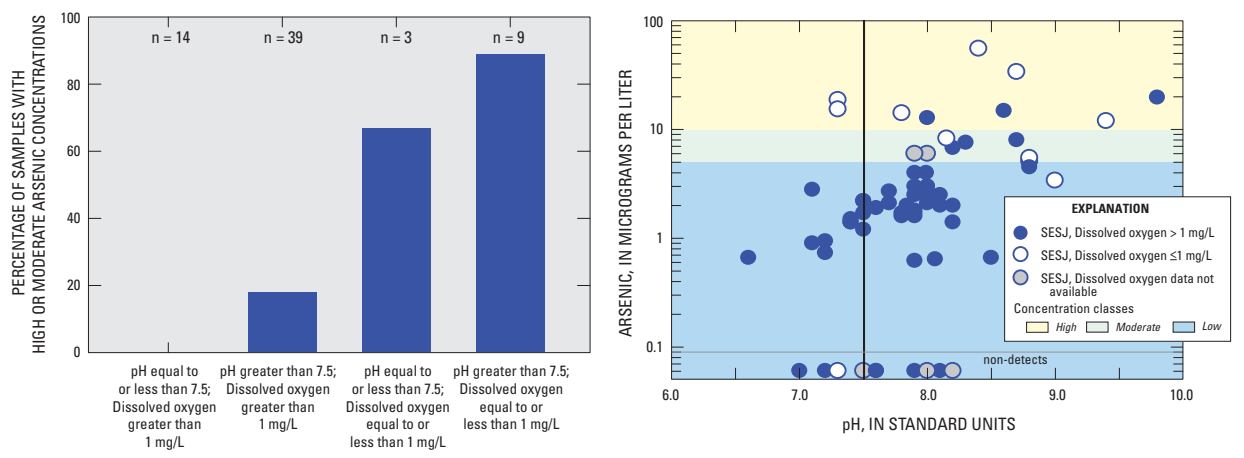

Nitrate is another constituent detected at high concentrations (6\%) in the primary aquifers. The human-health regulatory benchmark for nitrate (as nitrogen) is $10 \mathrm{mg} / \mathrm{L}$. High concentrations of nitrate result from human activities such as applicaton of fertilizer, animal waste, and septic systems. Nitrate concentrations are significantly higher in wells less than 250 feet deep than in deeper wells. Nitrate concentrations are generally low in groundwater with low $\mathrm{DO}(<1 \mathrm{mg} / \mathrm{L})$ because nitrate degrades under these conditions.

Arsenic and nitrate data collected for the GAMA Domestic Well Project is used in these analyses. The Domestic Well Project is administered by the California State Water Resources Control Board (http://www.swrcb.ca.gov/water issues/programs/gama/domestic_well. $\underline{\text { shtml). }}$.

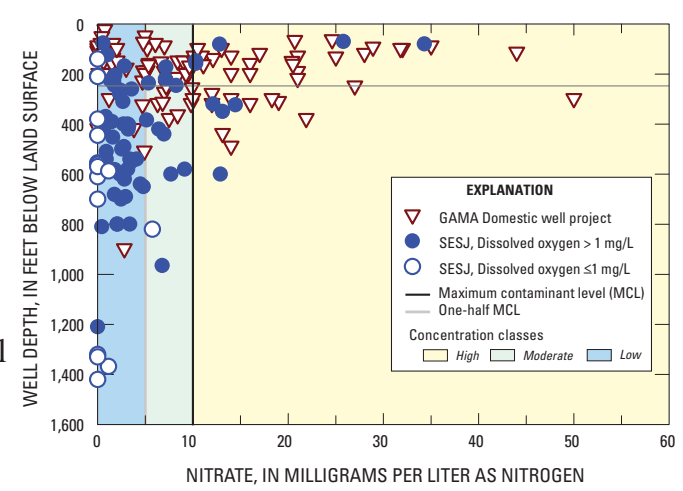

\section{By Carmen A. Burton and Kenneth Belitz}

\section{SELECTED REFERENCES}

Burton, C.A., and Belitz, Kenneth, 2008, Ground-water quality data in the Southeast San Joaquin Valley, 2005-2006-Results from the California GAMA Program: U.S. Geological Survey Data Series Report 351, 103 p. Available at http://pubs.usgs.gov/ds/351.

Burton, C.A., Shelton, J.L., and Belitz, Kenneth, 2012, Status and understanding of groundwater quality in the two Southern San Joaquin Valley study units, 2005-2006-California GAMA Priority Basin Project: U.S. Geological Survey Scientific Investigations Report 2011-5218, 150 p. Available at http://pubs.usgs.gov/sir/2011/5218.

California Department of Water Resources, 2003, California’s groundwater: California Department of Water Resources Bulletin 118, 246 p. Available at http://www.water.ca.gov/groundwater/bulletin118/ update2003.cfm.

Faunt, C.C., ed., 2009, Groundwater availability of the Central Valley aquifer, California: U.S. Geological Survey Professional Paper 1766, 225 p.

Stollenwerk, K.G., 2003, Geochemical processes controlling transport of arsenic in groundwater-A review of adsorption, in Welch, A.H., and Stollenwerk, K.G., eds., Arsenic in groundwater-Geochemistry and occurrence: Boston, Kluwer Academic Publishers, 475 p.

Wright, M.T., Belitz, Kenneth, and Johnson, Tyler, 2004, Assessing the susceptibility to contamination of two aquifer systems used for public water supply in the Modesto and Fresno metropolitan areas, California, 2001 and 2002: U.S. Geological Survey Scientific Investigations Report 2004-5149, 35 p.

\section{Priority Basin Assessments}

GAMA’s Priority Basin Project (PBP) assesses water quality in that part of the aquifer system used for drinking water, primarily public supply. Water quality in the primary aquifers may differ from water quality in shallower and deeper parts of the aquifers. GAMA's Domestic Well Project assesses water quality in the shallower parts of the aquifer system. Ongoing PBP assessments are being conducted in more than 120 basins throughout California.

The PBP assessments are based on a comparison of constituent concentrations in untreated groundwater with benchmarks established for the protection of human health and for aesthetic concerns for drinking water. The PBP does not evaluate the quality of drinking water delivered to consumers.

The PBP uses two scientific approaches for assessing groundwater quality. The first approach uses a network of wells to statistically assess the status of groundwater quality. The second approach combines water quality, hydrologic, geographic, and other data to help assess the factors that affect water quality. In the SESJ study unit, data were collected by the PBP in 2005-2006 and from the CDPH database for 2003-2005. The PBP includes chemical analyses generally not available as part of regulatory compliance monitoring, including measurements at concentrations much lower than human-health benchmarks, and measurement of constituents that can be used to trace the sources and movement of groundwater.

\section{For more information}

Technical reports and hydrologic data collected for the GAMA Program may be obtained from:

\section{GAMA Project Chief}

U.S. Geological Survey California Water Science Center 4165 Spruance Road, Suite 200

San Diego, CA 92101

Telephone number: (619) 225-6100

WE B: http://ca.water.usgs.gov/gama

\section{GAMA Program Unit}

State Water Resources Control Board

Division of Water Quality

PO Box 2231, Sacramento, CA 95812

Telephone number: (916) 341-5779 WEB: http://www.waterboards.ca.gov/gama 